The following paper posted here is not the official IEEE published version. The final published version of this paper can be found in the Proceedings of the IEEE International Radar Conference (2005 : Washington DC):pp. 5-9

Copyright @ 2005 IEEE.

Personal use of this material is permitted. However, permission to reprint/republish this material for advertising or promotional purposes or for creating new collective works for resale or redistribution to servers or lists, or to reuse any copyrighted component of this work in other works must be obtained from the IEEE. 


\title{
Defence Radar Development In Australia: 1939 To The Present
}

\author{
Donald H Sinnott, PhD, Centre of Expertise in Microwave Radar
}

Key Words: radar development, Australia, HF radar, SAR

\section{SUMMARY \& CONCLUSIONS}

Defence radar research and development in Australia is today largely, but not exclusively, confined within Australia's Defence Science and Technology Organisation, DSTO, and its R\&D collaborators in universities. Radar has a long history in Australia, dating back to World War II links with British defence radar development, and radar R\&D continues to be an important focus within DSTO. It is impossible, in the context of a brief conference paper, to give other than the broadestbrush picture of Australian radar development over a halfcentury or more. So the approach taken is necessarily highly selective and focuses specifically on several illustrative development projects, in an attempt to convey the flavour of national radar research priorities, the way they drive R\&D and likely future directions.

Despite the escalating requirement for a national skills base in defence radar and allied technologies there are currently legitimate concerns about the robustness of this base. Recruitment of high-calibre researchers into the field of radar and management of radar research careers are issues currently presenting major challenges. A number of initiatives are in place linking DSTO with university research; a recent effort to enhance the stature and visibility of radar research in Australia is the establishment of the Centre of Expertise in Microwave Radar as a joint venture between DSTO and Adelaide University.

\section{INTRODUCTION}

The title of this paper promises far more than can be delivered in a few pages. Its essential messages are that Australia has been involved in radar development since 1940, that current defence radar research and development is for the most part carried out within, or sponsored by, DSTO and that over the years this Organisation has delivered not only sound advice and judgements about radar technology to the Australian Defence Organisation but also some outstanding development projects that respond to national defence radar priorities.

Australia's geography, history and geostrategic circumstances drive national priorities for radar and other sensing and reporting technologies, as they do for all defencecritical technologies. Drivers particularly relevant to radar development in Australia include the following.

- An immense island landmass (comparable in size to the contiguous states of the USA) that forces attention on radar technologies applicable to wide- area and readily-deployable coastal and air-approach surveillance.

- Australia's position as a Western alliance partner requires flexible military radar networking systems able to respond not only to Defence of Australia challenges but international alliance commitments.

- A modest-size population (20 million) and geographic isolation from centres of international research that oblige a commitment to connection and integration with the mainstream of radar $\mathrm{R} \& \mathrm{D}$ in order to leverage indigenous efforts.

These enduring drivers come through clearly in the selection of radar development projects discussed in what follows.

\section{AUSTRALIAN RADAR IN WORLD WAR II AND THE IMMEDIATE POST-WAR YEARS}

As a consequence of its geography, long-range radio communications was a priority for Australia as early as the 1920s. This provided a fertile environment for the subsequent development of radar technology when, as a deliberate policy, the British government shared its radar discoveries with Commonwealth countries as early as 1939 [1] and well before the sharing of British radar developments with the US from 1940. During World War II, a number of unique radar sets were produced in Australia, adapted from British and US designs, to suit the particular operational and environmentallyextreme conditions of the Pacific theatre. They were produced in significant numbers and used by both US and Australian operational units. For example, 1300 units of the Britishdesigned ASV MkII were produced in Australia [2] and the Australian fast-deployment light-weight air-warning radar (LW/AW) was described as "the best in the world for conditions of jungle, air transport and beach landings" [3].

During World War II Australian radar research and development had been carried out under the auspices of the then Council for Scientific and Industrial Research (CSIR, now CSIRO) at its Sydney University Radiophysics Laboratory. At war's end there was an expectation that this laboratory would continue in this activity and, moreover, would extend its research into other military technologies. But, relying on its 1920 charter giving CSIR independence of action, its Chairman adamantly refused to entertain any further military R\&D within CSIR. This was perhaps a blessing in disguise for it forced Australia to initiate an independent agency for defence research, with specifically defined 
objectives, leading ultimately to today's DSTO. It also underlined the importance of growing Australia's own cadre of defence research staff, linked to but outside an academic environment, and a program commenced in 1947 whereby promising science and engineering trainees were sent to the UK for training, including at major universities like Cambridge and Oxford, in fields including those crucial to radar development. This injection of trained staff, along with migration of a number of key radar experts from Britain, gave Australia the crucial kick-start in radar essential for future progress in the field.

In an interesting twist, Dr E G Bowen, the first recruit of British radar pioneer Watson-Watt in their pre-World War II radar development program and architect of Britain's earliest airborne radar development, emigrated to Australia to become Chief of CSIR's Radiophysics Laboratory immediately after the war, just as it turned its principal attention to the then infant science of radio astronomy and abandoned further work on radar.

From 1946 the major driver for Australian radar technology development came from the British-Australian Joint Project. The Project, active for two decades, supported Britain's ambitions to pursue development of an independent nuclear deterrent and its delivery systems, following passage by the US Congress of the 1946 McMahon Act suspending assistance to the UK in atomic energy [4 ]. A major rocket range was established in Australia and used not only for Joint Project firings but also US and Australian rocket projects, the latter including the successful launch of Australia's first satellite, WRESAT, in 1969. Among the more enduring outcomes from this period for Australia was the establishment of knowledge, skills and hands-on experience acquired from developing, using and sustaining large-scale rocket range facilities, including radar systems. In particular, it provided opportunities for experimental investigations of rocket-caused disturbances in the ionosphere, opening for Australian researchers the field of HF skywave over-the-horizon radar (OTHR), which is discussed in Section 3.1.

\section{THE DEFENCE SCIENCE AND TECHNOLOGY ORGANISATION}

After the withdrawal of CSIR from the field, the Australian defence research laboratories of what is now the Defence Science and Technology Organisation (DSTO), in South Australia, took over prime national responsibility for defence radar research.

While EG Bowen went to CSIR's Radiophysics Laboratory to follow a non-radar career, the Defence laboratories in South Australia saw a significant number of other celebrated British war-time radar experts join their ranks. Among them was WAS Butement, Director of Scientific Research, UK Ministry of Supply (1940-1946) who is credited (with PE Pollard) with the first demonstration of radar in Britain (1930, pre-dating the Watson-Watt and Wilkins 1935 demonstration). In Australia he became Chief (Defence) Scientist (1949-67). Another was RJ Dippy, a member of Watson-Watt's Bawdsey Manor team in the UK's war-time radar development and inventor of the blind- bombing system Gee [5]. Dippy became a Divisional head of electronics research. Most significantly for DSTO's subsequent achievements in HF radar, John AW Strath, a highly capable but essentially unreported participant in UK radar development, came to Australia in 1952 - his preeminent role in Australian HF radar development is picked up in the next section.

DSTO continues as lead national agency in radar, with links into academic research and fortified by important international defence research agreements with allied countries. Principal among these is the Technical Cooperation Program (TTCP) in which the US, UK, Canada and New Zealand cooperate with Australia in a range of military technologies, including radar. Among the many benefits this program has delivered to Australia was opening of a US/Australia dialogue on HF radar, to which we now turn.

\subsection{Jindalee Over-the horizon radar}

The most celebrated Australian-developed radar systems deriving from DSTO R\&D is the skywave HF OTHR system, the Jindalee Operational Radar Network, JORN. Its genesis in Australia dates from experimentation in the early 1950s, capitalising on opportunities for large-scale HF radar probing of ionospheric disturbances generated by rocket launchings under the UK/Australia Joint Project discussed above. The HF backscatter observations continued into the end of the Joint Project in the mid 1960s.

This HF radar investigations included some early attempts to implement skywave OTHR which failed on account of the then primitive technologies available for signal generation, receiving systems and signal processing. As has been reported [6], the US was engaged in similar work in the same period and, with access to far greater resources, forced the pace of development of the technologies required to provide an OTHR demonstration by 1961. A crucial focus for US technological development was a "magnetic drum integrator" or signal processor which has been acknowledged as "the key element in the success achieved with OTHR" [6].

Without the resources and official support required to address such technology development, progress in an Australian OTHR program was delayed until 1968 when John Strath, under the umbrella of TTCP, made connection with the then heavily-classified US HF radar programs. This connection was the circuit breaker for further Australian work in OTHR: given evidence of US success in OTHR Strath had much-needed credibility and proceeded to develop strategic assessment papers that showed the value to Australia of the long-range wide-area air-defence capability such radar technology could provide. Further, access to US technology and surplus HF equipment gave hope for a relatively economical and fast-track Australian development program, to be designated Jindalee.

The development by DSTO of the Jindalee demonstrator OTHR system, from the early 1970s, initially relied to a significant extent on cooperation with the US and links into the several strands of US HF radar development that derived from the NRL Madre system [6]. After a period of DSTO 
development and credibility-building and an extended contractual phase the Jindalee Operational Radar Network (JORN) formally entered operational service in April 2003 as a prime long range defence sensor for Australia. During the long currency of the Jindalee development project US interest in HF radar for defence against strategic bombing waned, and Australia increasingly made its own way in the technology so that what has now been implemented as JORN is a unique and highly-developed capability.

The development of Jindalee, including both its technical and credibility-building challenges, has been described by the author previously [7]. Research continues into adding value and enhancing performance and capability of JORN, most particularly in terms of signal processing and sensor networking, as more extensive operational experience is gained.

\subsection{Ingara}

Since 1990 DSTO has conducted a development program in airborne synthetic aperture radar (SAR). A flexible and innovative X-band SAR was developed by DSTO and installed, initially, in a Dakota aircraft operated by the research and development unit of the Royal Australian Airforce. Airborne trials programs began in 1993 and were subsequently expanded, addressing an Army land-surveillance mission, using a Beech King Air aircraft. On-board SAR processing was provided as well as a high-capacity data link for on-ground processing [8]. Later in the program the SAR system, now badged Ingara, became part of a flexible airborne multi-sensor ISR system with impressive SAR, MTI, visible and IR sensing capabilities carried in a Raytheon Beech 1900C aircraft. Parameters of the radar are given in Table 1.

Other research continues on value-adding to imagery received from the Ingara platform. Current activity includes such topics as exploitation of polarimetry [9] and repeat-pass interferometry and a major DSTO research activity has been focussed on analyst detection support facilities for the system [10]. The newly-established Centre of Expertise in Microwave Radar (see Section 5) has a particular research focus on polarimetric and interferometric SAR and it is expected that collaborative research programs will be supported through access to the Ingara radar.

\subsection{HF surface wave radar}

Deriving from the development of the Jindalee sky-wave HF radar, extensive R\&D has been carried out into HF surface wave radar and several demonstrator systems have been fielded. There have been trials based around Darwin in northern Australia, in which DSTO, the Cooperative Research Centre for Sensor Signal and Information Processing (CSSIP see Section 5) and industry collaborated. In early 2003 the Department of Defence and Customs Coastwatch issued a three-year contract for an extended deployment of a surface wave radar system in the North of Australia [12]. Valuable research into phenomenology and system design was carried out in the Darwin deployment [13].
Table 1: Ingara Imaging Radar Parameters

\begin{tabular}{|l|l|}
\hline \multicolumn{1}{|c|}{ Parameter } & \multicolumn{1}{|c|}{ Characteristics } \\
\hline Aircraft & Raytheon Beech 1900C \\
Typical Altitude & $7900 \mathrm{~m}\left(25,000^{\prime}\right)$ \\
Typical Speed & $110 \mathrm{~m} / \mathrm{s}$ \\
Radar Frequency Range & $9.8-10.4 \mathrm{GHz}$ \\
Chirp Bandwidths & $6 \mathrm{MHz}-600 \mathrm{MHz}$ \\
ADC & $100 \mathrm{MHz}$ Bandwidth, I/Q \\
Polarimetric Tx Power & $1 \mathrm{~kW}$ \\
Polarimetric Antenna & $28.7 \mathrm{~dB}$ \\
Directivity & $<-25 \mathrm{~dB}$ \\
Polarization Cross Talk & $\mathrm{INU}$ and Differential GPS \\
Motion Sensing & \\
Radar Modes & $12-48 \mathrm{~km}$ swath @ 2 - $8 \mathrm{~m}$ \\
Stripmap Single Pol. & res, multi-look processing \\
Stripmap Full Pol. & $\leq 8 \mathrm{~km}$ swath @ 4m resolution, \\
Spotlight Single \& Full & $4 \mathrm{looks}$ \\
Pol. & \\
Maritime Scan & $2 \mathrm{~m}$ resolution 4 \\
Maritime ISAR & $0.3 \mathrm{~m}$ resolution \\
MTI & $12 \mathrm{~km}$ swath \\
Geocoding Accuracy & $<20 \mathrm{~m}$ absolute \\
& \\
\hline
\end{tabular}

\subsection{Radar knowledge-building for defence acquisition advice}

Although Jindalee became a defence operational system it is atypical for Australian defence research to be carried to this point, at which a contractor is required to deliver $a b$ initio a uniquely-specified system modelled on a DSTO demonstrator. For the most part, Australian defence R\&D aims at delivering "smart buyer" capabilities in defence procurement, through having an informed and experienced base from which to develop procurement decisions, possibly including specifications for an OEM to adapt existing international designs. While it is unclear whether Ingara will fall into this pattern, most other current Australian defence research in radar does. There is much current activity in support of radar acquisition and introduction-into-service projects in which equipment is sourced off-shore, in some cases with significant Australian involvement in development. Current projects of this type include the Raytheon APG -73 radar upgrade for the F/A-18, the Elta ELM 2022(V)3 radar replacement for the P3C, the Northrop Grumman radar for the Wedgetail AEW\&C program and initial involvement in the US JSF program.

Other DSTO radar research supports a wide range of Defence acquisition and support. The work includes a strong emphasis on radar phenomenology, phased arrays, signal processing and tracking. 


\section{DEFENCE RADAR DEVELOPMENT IN AUSTRALIAN INDUSTRY}

For the most part Australian defence radar industry is derivative from off-shore industry parents and most operational Australian defence radar is international in design, with some adaptation to local requirements. Some off-shore companies operating in Australia carry out radar research incountry and DSTO seeks to ally with them in these endeavours, in order to promote national capability in radar research. There are some indigenous companies manufacturing radar sub-systems and, in at least one case, complete radar systems aimed at the defence market. The development of the phased array S-band radar CEA-FAR by CEA Pty Limited in Canberra is an example of what can be achieved [14].

\section{DSTO RADAR RESEARCH COLLABORATION WITH UNIVERSITIES}

For some years DSTO has been sponsoring research in the University of Melbourne's Centre of Expertise in Networked Decision and Sensor Systems (CENDSS). This Centre carries out research into sensor scheduling and adaptive radar signal processing, complementing and sustaining in-house DSTO programs. It has multiple industry participants from both Australia and the US, as well as funding from the US Defense Advanced Research Projects Agency (DARPA) and the US Air Force.

A second major focus for university-based research has come through DSTO's participation over a 13-year period in the Centre for Sensor Signal and Information Processing (CSSIP). A broad program of radar research has been carried out by CSSIP, specifically supporting in-house DSTO programs in skywave and surface wave radar, SAR and ISAR, and producing a number of graduates in radar specialisations. CSSIP is now completing its government-supported term and will cease operations in mid-2006.

A new cooperative venture, more specifically focused on microwave radar phenomenology and technology, the Centre of Expertise in Microwave Radar (CoEMR), was established in 2004. The CoEMR is a joint venture between DSTO and the University of Adelaide, in part addressing the perceived fragility of DSTO's in-house base in microwave radar. The Centre seeks to provide a focus for microwave radar research expertise in South Australia and to explore new commercial and defence applications of this technology. It embraces fundamental research, specialist training courses and national and international collaboration. Key areas of activity include the following.

- High resolution 2-D and 3-D microwave imaging techniques

- Radar polarimetry, polarimetric interferometry and its applications

- Ultra wide band (UWB) technology and applications

- New techniques for microwave remote sensing of land, sea and ice surfaces

- Quantitative vegetation and forest mapping using multi-parameter radar
- Clutter and target characterisation in multi-parameter radar environments

- Novel electromagnetic modelling techniques

It is expected that the CoEMR will enter into formal collaboration and shared-funding programs internationally and a start has been made already with its appointment as Principal Investigator on the dual-satellite X-band Tandem-X phase 1 mission study directed by the German space agency, DLR. CoEMR is also an official member of the ALOS/PALSAR international calibration and validation team and will take part in polarimetric phase calibration of the new $\mathrm{L}$ band phased array SAR system to be launched by JAXA in 2005. Other avenues of international collaboration are being actively pursued.

DSTO also has a research and commercialisation agreement with National ICT Australia (NICTA), a major federally-funded centre that offers some opportunities for collaboration with a range of universities and industry on radar signal processing.

\section{THE FUTURE FOR RADAR DEVELOPMENT IN AUSTRALIA}

One of the clearly discernable trends within DSTO is that the day of development projects is all but over. The environment in which projects like Jindalee or Ingara could be carried forward, largely in-house, no longer exists, under the pressure on DSTO to concentrate resources on its "expert professional advice" role and leave developmental projects largely to industry. DSTO manages Defence's Capability Technology Demonstrator program, which encourages DSTO/industry development projects and which may be seen as the lineal descendant of the in-house projects environment days.

While there can be little argument against the logic of this trend in terms of efficient delivery of immediate defenceadvice outcomes, what it risks is denying opportunities for many young engineers and scientists (and some not so young) to get real hands-on experience in radar development. As a result it has potential to foster a dangerous arm-chair expert environment for delivery of advice by DSTO to Defence in which there is only second-hand experience and superficial knowledge on which to base judgements. This danger has been recognised and renewed efforts are being made to allow advisers on radar technology to source their advice in a depth of knowledge and actual experience.

On the assumption that this focus on hands-on experience is followed through, the future for radar development in Australia is likely to see a broad mix of DSTO/university/industry research leading to demonstrator projects. International collaboration will be increasingly important. The drivers highlighted at the end of section 1 will continue to operate and hence it is reasonable to expect further innovation in radar to suit the circumstances of Australian defence. 


\section{REFERENCES}

1. E. G. Bowen, Radar Days, Adam Hilger, IOP Publishing Ltd, Bristol, 1987, p197.

2. Ibid, p209.

3. A. T. Ross, Armed and Ready: the industrial development and Defence of Australia 1900-1945, Turton and Armstrong, Sydney, 1995, p425.

4. W. Reynolds, "In the Footsteps of Manhattan: Australian Defence Science and the Quest for the Atomic Bomb", Ch 4 in Arming the Nation, Ed F Cain, Canberra, Australian Defence Studies Centre, 1999, p40.

5. IEEE Transactions on Aerospace and Electronic Systems, AES-2, No 4 (July 1966), pp475-481.

6. J. M. Headrick, M. I. Skolnik, "Over the horizon radar in the HF band", Proceedings IEEE, vol 62, June 1974, pp 664-673.

7. D. H. Sinnott "The development of over-the-horizonradar in Australia", DSTO Bicentennial Monograph, 1988.

http://www.dsto.defence.gov.au/corporate/history/othr/in dex.html

8. Stacy, N.J.S.; Burgess, M.P.; Muller, M.R.; Smith, R., "Ingara: an integrated airborne imaging radar system", Proceedings of IGARSS '96, 27-31 May 1996, pp. 1618 $-1620$

9. N. J. Stacy, M. L. Williams, M. Preiss, A. Goh, D. Badger and D. Crisp, "Analysis of Ingara Fully Polarimetric X-Band SAR Imagery of Australian Terrain", 12th Aust. Remote Sensing and

Photogrammetry Conference, Fremantle, Australia, 2004.

10. N. J. Redding, D. I. Kettler, G. Blucher, P. G. Perry, "The Analysts' Detection Support System for Deploying a Network of Target Detection and Recognition Algorithms in SAR Exploitation" Proc RADAR 2003, IEEE cat no 03EX695C, pp 448-453.
11. M. Preiss, D. Gray, N. Stacy, "Change Detection in Repeat Pass Interferometric Synthetic Aperture Radar" Proc RADAR 2003, IEEE cat no 03EX695C, pp 98-102.

12. R. Hill, "Border surveillance boosted with new radar", Australian Minister for Defence Press Release, 25 Feb 2003.

http://www.minister.defence.gov.au/2003/025250203.doc

13. S. J. Anderson, P. J. Edwards, P. Marrone, Y. I. Abramovich, "Investigations with SECAR - A Bistatic HF Surface Wave Radar" Proc RADAR 2003, IEEE cat no 03EX695C, pp 717-722.

14. CEA Pty Limited, "CEA-FAR (3D) Radar", Company information, http://www.cea.com.au/r\&d/r\&d.html

\section{BIOGRAPHY}

Donald (Don) H Sinnott was born in Melbourne, Australia, in 1944. He holds the degrees of BE(Electrical) and MEng Sc from Melbourne University, Australia, and $\mathrm{PhD}$ (Syracuse University).

$\mathrm{He}$ is currently a consultant in electronics systems and Adjunct Professor of Radar Systems with the University of Adelaide. He is part-time strategic adviser to Adelaide University's Centre of Expertise in Microwave Radar, a joint venture with Australia's Defence Science and Technology Organisation (DSTO). He was previously Professor of Sensor Systems with the University of South Australia and CEO of the Cooperative Research Centre for Sensor Signal and Information Processing (CSSIP). Prior to this he held positions as Chief of several Research Divisions in DSTO and First Assistant Secretary Science Policy in Australia's Department of Defence in Canberra. In his active research career his specialisation was in computational electromagnetics and antennas.

Don is a Fellow of the Institution of Engineers Australia and of the IEEE.

Address: 37 Janlyn Rd, Vista, SA, 5091, AUSTRALIA

don.sinnott@ieee.org 